\title{
Introduction to the issues in honor of Leonid Hurwicz
}

\author{
John Ledyard
}

Published online: 28 March 2009

(C) Springer-Verlag 2009

In my second year in graduate school in 1965, Stanley Reiter gave me copy of "Optimality and Efficiency in Resource Allocation Processes" published in 1959 by Leonid Hurwicz. The article had a remarkable effect on me. I knew immediately that these were the questions I went into economics to study and the precision with which I wanted to carry out that study. At the time there was no word for the area, today we call it Mechanism Design. The field and Leo's role in creating it were recognized with a Nobel Prize in 2007.

But this volume of papers is about more. Throughout his career, Leo's indefatigable enthusiasm, his intellectual curiosity, his willingness to share ideas openly, and his gentleness inspired all who came into contact with him. He nurtured many students, co-authors, and colleagues. With Tom Marschak, Roy Radner, and Stan Reiter, Leo created the Decentralization Conference that served as an intellectual home to many of us early in our careers when Mechanism Design and Mathematical Economics were not exactly at the center of the profession. The conference continues running today, after more than 40 years, and still serves as a place where good young theorists can feel at ease.

Much has been already written about Leo and his work. I need not duplicate that here. The breadth of the topics, the quality of the work, and the eagerness of the 21 authors to participate in these issues speak volumes about the admiration and warmth that we all continue to feel for Leo. His presence in these articles, as well as in much of modern economic theory, is undeniable. That presence will continue long into the future.

Because of the large number of authors who wanted to contribute papers, we are issuing this tribute to Leo in multiple volumes which will appear over the next year.

J. Ledyard ( $ه)$

Division of the Humanities and Social Sciences, California Institute of Technology,

MC 228-77, Pasadena, CA 91125, USA

e-mail: jledyard@hss.caltech.edu 